\title{
The impact of ecological aspects on sustainable development of resort territories (example of the Krasnodar region, Russia)
}

\author{
Evgenia Vidishcheva $^{1}$, Yuriy Dreizis ${ }^{1, *}$, and Andrey Kopyrin ${ }^{1}$ \\ ${ }^{1}$ Sochi State University, 94-1, Plastunskaya str., 54000, Sochi, Russia
}

\begin{abstract}
Rapid increase of economic affairs, expansion of human activity, as well as accelerating growth of man-made factors increase the pressure on the environment as the basis of human life. Environmental degradation can bring into challenge both sustainability and future development of territories. Nowadays, regions and countries are on the way to sustainable development, as the most reasonable in terms of rational and effective use of resource potential. According to the concept, environmental conditions, economic and social stability are the three pillars of sustainable development. Importance of environmental component has been underestimated for a long period. However, environmental «health» and balance determine the dynamics, duration and direction of development. The purpose of the study is to analyze the impact of environmental component on the sustainability of resort territory using the example of the Krasnodar region indicators.
\end{abstract}

\section{Introduction}

The modern economic system is characterized by a certain degree of unpredictability and the presence of a number of serious destabilizing factors. In this regard, the relevance of studying and applying sustainable development practices increases, since the state of sustainability reduces the risk of unplanned losses. There are different approaches to defining the concept of sustainability. For example, Stoddart (2011) defines sustainability as the efficient and equitable distribution of resources intra-generationally and inter-generationally with the operation of socio-economic activities within the confines of a finite ecosystem [1]. Thomas (2015) focuses on human activities and their ability to satisfy needs without exhausting the productive resources [2]. Thus, sustainability in relation to development implies a long-term balanced development of the territorial entity, accompanied by a moderate use of resources and taking into account the interests of all stakeholders. In the framework of this study, the sustainability of territories of resort and recreational specialization is of interest.

It is worth noting that the application of the concept of sustainability to the development of resort territories is most relevant and necessary in modern conditions $[3,4]$. On the way to maximize profits and accelerate the achievement of development targets, the load on the territory increases, which, in turn, leads to an irrational exhausting of tourist and recreational potential and threatens the natural and recreational value of the territory. The contradictions

* Corresponding author: Yurid2006@yandex.ru 
aggravation between the effective use of natural resources and man-made impact on the environment in the process of ensuring human life has particularly highlighted the importance of constant monitoring and optimization of the environmental sustainability of territorial development.

The state of stability of the resort territory means the simultaneous achievement of the following development characteristics: economic stability, positive environmental situation, tourist demand for the territory, moderate anthropogenic load, and social satisfaction of the local community [3, 4]. These elements of sustainable development fit into the generally accepted concept of sustainable development, which includes 3 components: economic, social and environmental (ecological). The ecological component of development is represented by a positive environmental situation and moderate anthropogenic load. The role of these characteristics for resort regions is very large, since natural resources are the basis of most recreational territories and clusters.

Indicators of environmental sustainability of resort territories are important criteria that reflect the state of the regional economy $[3,4]$. The higher the environmental efficiency of economic development and functioning, the higher the stability of territorial systems. Underestimating the priority of the environmental factor and the social value of natural goods leads to an erroneous idea of the priority of solving first economic and social problems, and then environmental ones. Further development of resort territories of the Krasnodar region largely depends on the effective use of natural potential [3, 4].

This study assessed the environmental stability of resort territories of the Krasnodar region, identified the contribution of the environmental component to the comprehensive sustainable development of the region, and determined the correlation between the social, economic and environmental indicators of the region, and formulated recommendations to improve the sustainability by optimizing the environmental situation.

The methodological basis of the study is the techniques and methods of the system approach, theoretical and empirical generalizations, logical analysis and synthesis, as well as the method of comparison, graphical constructions, and others.

\section{Results and discussion}

There are two most important components of environmental sustainability of resort territories of the Krasnodar region. First - air purity (low gas content). A wide forest area and exposure to the seacoast help to clear the air masses, and in many ways determine the choice of tourists who want to leave industrial cities and megacities for a holiday. The second element that is most relevant for areas that specialize in beach tourism is the quality of water resources. These and other factors determine to some extent the environmental sustainability of territorial development, while at the same time affect the economic and social component of development. At present, as in previous years, the Krasnodar region owes much of its development to natural and recreational resources. Despite the significant diversification of the region's economy, the lion's share of the gross product of resort territories is formed due to the functioning of the tourist complex. In addition, serious damage to the natural and recreational potential can offset any socio-economic and industry achievements, including those related to the development of the tourism industry in the region.

To effectively assess the role of environmental sustainability in the development of resort territories, it is necessary to assess the environmental situation in the region. The overall environmental situation in the region is assessed using the developed methodology, which includes such indicators as environmental protection expenditures, dynamics of atmospheric emissions (from stationary sources, road transport), ratio of water samples that do not meet sanitary requirements, and others. Consider the most significant indicators in terms of its impact on the stability of the territory. 
Air pollution indicators are estimated based on data on the amount of emissions from stationary sources of pollution, as well as emissions from road transport. Overall, the region's emissions increased by almost 70\% since 2008 till 2018. The share of stationary sources of pollution in this amount according to the latest official data is $59 \%$. As for road transport, despite the steady growth in the number of road transport in the region, its contribution to air pollution is less than $1 \%$.

Stationary pollution sources include industrial enterprises, boilers and other capital facilities that emit pollutants into the atmosphere. Different number of such objects are functioning in all regions, regardless of specialization, the absence or presence of an industrial complex. The assessment of the activity of stationary pollution sources operating on the territory of the Krasnodar region resorts is presented in table 1.

Table 1. The dynamics of emissions from stationary pollution sources, 2014 -2017 (source: Federal state statistics service [5-9]).

\begin{tabular}{|c|c|c|c|c|c|c|}
\hline & \multicolumn{2}{|c|}{ Anapa } & \multicolumn{2}{c|}{ Sochi } & \multicolumn{2}{c|}{ Gelendzhik } \\
\cline { 2 - 7 } & $\mathbf{2 0 1 4}$ & $\mathbf{2 0 1 7}$ & $\mathbf{2 0 1 4}$ & $\mathbf{2 0 1 7}$ & $\mathbf{2 0 1 4}$ & $\mathbf{2 0 1 7}$ \\
\hline $\begin{array}{c}\text { Number of objects with stationary } \\
\text { atmospheric air pollution sources, } \\
\text { units }\end{array}$ & 35 & 40 & 75 & 62 & 18 & 20 \\
\hline $\begin{array}{c}\text { Pollutants released into the atmos- } \\
\text { phere from stationary sources, } \\
\text { thousand tons }\end{array}$ & 3.257 & 2.696 & 7.398 & 6.482 & 0.363 & 0.575 \\
\hline $\begin{array}{c}\text { The amount of pollutants released } \\
\text { into the atmosphere per 1 object } \\
\text { with a stationary pollution source, } \\
\text { thousand tons }\end{array}$ & 0.093 & 0.067 & 0.099 & 0.105 & 0.020 & 0.029 \\
\hline
\end{tabular}

Based on the data from the table, we can conclude that, despite the increase in the number of objects - pollution sources in the Anapa city, the volume of emissions to the atmosphere and the average volume of emissions from one object is reduced. In Sochi city, the number of stationary pollution sources has significantly decreased, but the volume of pollution per 1 object has slightly increased in 2017 (in comparison with 2014). As for Gelendzhik, the number of polluting objects increased by $11 \%$, the volume of emissions - by 1.6 times, and the volume of emissions per 1 object increased by $43 \%$ during the period under review. According to data for 2017, the maximum volume of emissions and polluting objects is in the Sochi city. In addition, the average volume of emissions per 1 polluting object in Sochi exceeds the same indicator of Anapa and Gelendzhik by 1.6 and 3.6 times respectively in 2017. In 2014, the difference was 6 times compared to Gelendzhik and 2 times - to Anapa.

Obviously, there is no common trend among resort cities. The total volume of emissions in the Krasnodar region has increased by 2 times over the same period. It is interesting that the region's indicators were doubled during 2018, and demonstrate an increase of more than 4 times in the period from 2014 to 2018 . However, it is worth mentioning that the share of the three above-mentioned resorts in the total emissions volume is only $2 \%$ according to data for 2017.

Considering the differentiation of the entities under study by area and population density, it is advisable to calculate the volume of emissions per unit area and per capita. The total amount of air emissions from all sources in the region per capita increased from 0.16 to 0.25 tons/person in the period from 2008 to 2018. The amount of emissions per unit area is 18.3 tons $/ \mathrm{km}^{2}$ in 2018 , which is $70 \%$ higher than in $2008-10.8$ tons $/ \mathrm{km}^{2}$. To compare the load on resort territories, need to analyze the emissions volume from stationary sources. The results based on the processing of official data are shown in Fig. 1. 
According to the calculation, the resort Anapa city is in the worst situation. This situation was largely caused by the relatively small area of the municipality. Therefore, for the most reliable estimate, let's turn to the per capita calculation (Fig. 2).

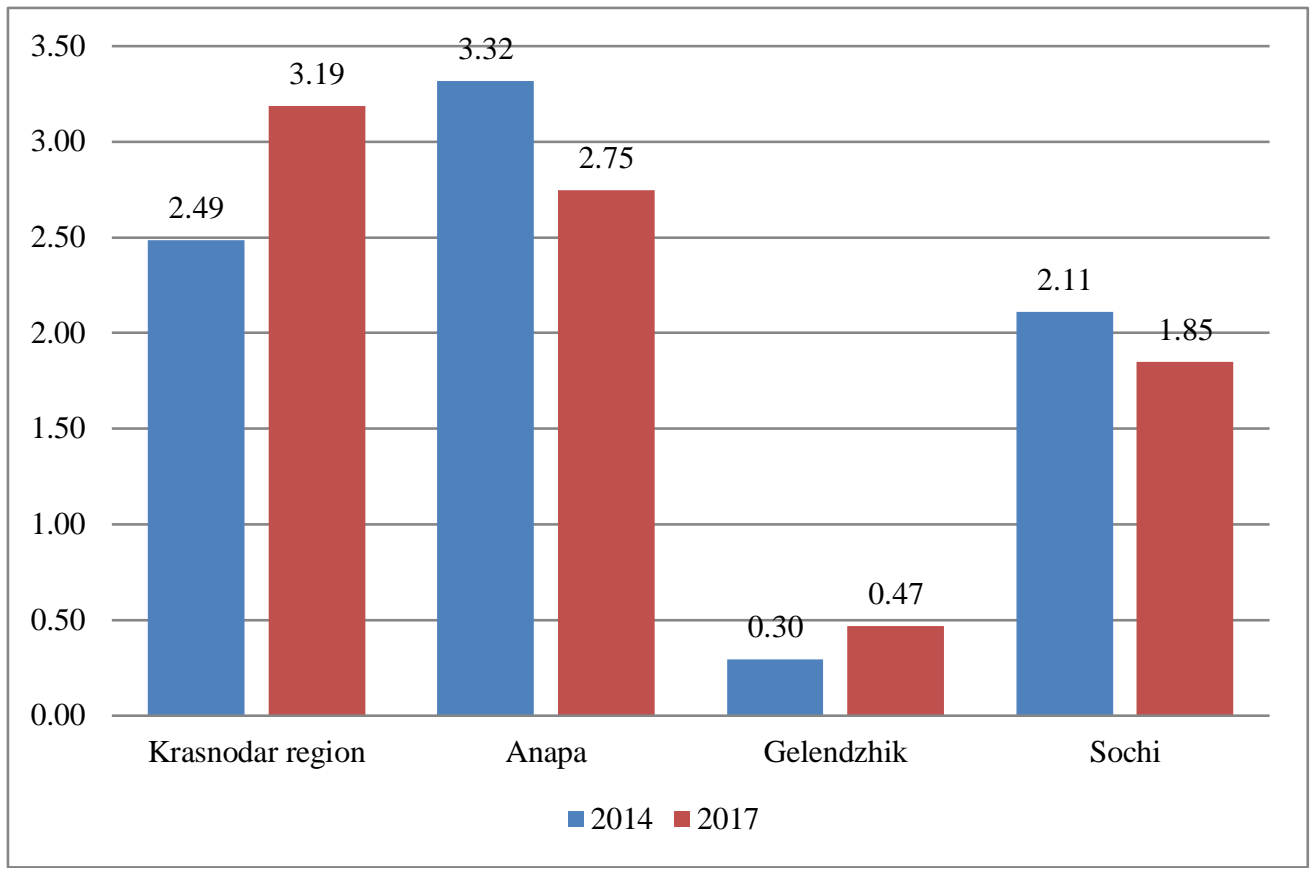

Fig. 1. Dynamics of emissions from stationary pollution sources per unit area, tons $/ \mathrm{km}^{2}$ (calculated by the author based on [5-9]).

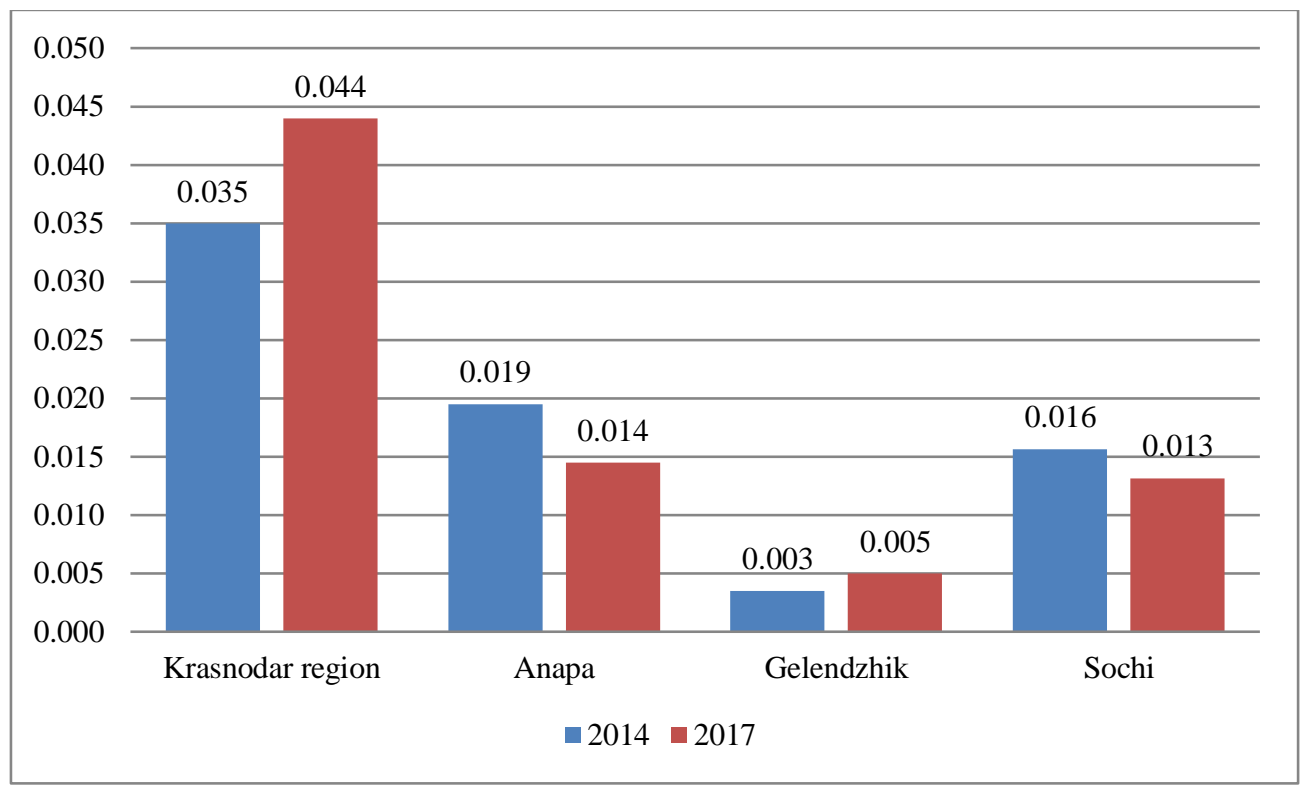

Fig. 2. Dynamics of emissions from stationary pollution sources per capita, tons/person (calculated by the author based on [5-9]). 
The indicator of the pollution volume per capita in the resort territories is significantly less than in the whole region, which indicates the least expressed pollution of these territories in comparison with entities of other specialization. The most favorable situation is observed in Gelendzhik city, where the minimum concentration of emissions per capita is recorded despite a small increase in 2018.

The next significant factor of the tourist demand for the resort territory of the Krasnodar region is the Black sea. Analysis of water samples in dynamics, carried out by the Ministry of natural resources of the Krasnodar region, showed that the ratio of water samples that do not meet sanitary requirements in 2018 decreased. For the period under review (2014-2018), microbiological indicators identified the most noticeable deviations of water samples from the standard. The largest number of cases of water non-compliance with regulatory parameters was fixed in the Sochi city, the leader in the water purity is the Anapa resort city. The indicator of the maximum permissible concentration of marine water pollution has a negative trend in terms of lead content and oil pollution. A positive increase is also observed in the concentration of iron. A serious risk factor is the discharge of contaminated wastewater into the water area. It goes without saying the dynamics of wastewater discharge is not as sharply as air pollution. Periods of growth are replaced by declines and vice versa. The total increase for the period under review was 7\%, although only from 2009 to 2012 the total volume increased by $23 \%$, but the final figure was smoothed by further periods of polluting discharges reduction. The moderate level of wastewater discharge is due to strict requirements of the Water code that prohibit the discharge of wastewater in coastal zones. However, in April of this year, it became known about the appeal of deputies of the Legislative Assembly to the State Duma with the initiative to amend these provisions of the Code. In particular, it is proposed to provide economic entities with the opportunity to discharge wastewater treated to the established standards in the water bodies of the second zone of sanitary protection districts [6]. This decision is justified, first, by the large number of concluded water use agreements, and secondly - by the potentially difficult situation for a number of housing and utilities companies and health resorts, provoked by the requirements of the code.

It should be noted that funds are regularly allocated from the both regional and federal budgets for environmental protection activities. About 70 million rubles were spent on environmental protection in the Krasnodar region since 2012 to 2018 . At current prices, annual expenses have increased by 9.7 million rubles since 2012. Even taking into account inflation, the amount of funding increased by $52 \%$ during this period. A high level of funding by the municipal authorities was also noted among the resort territories under study in 2018: Anapa - 11141.13 million rubles, Gelendzhik-1050.04 million rubles, Sochi-4513.79 million rubles [10-12].

The effectiveness of implemented measures is largely determined by the ratio of environmental efforts and anthropogenic load. The indicator of anthropogenic load for the region and its resort areas was calculated based on data on the number of people registered and living in the territory. According to this indicator, the population density increases in the region and resort municipalities. Consequently, the anthropogenic load increases. In the least favorable position is the Anapa city, where the number of inhabitants per square kilometer is more than 2 times higher than the regional indicators. The city of Sochi is at intermediate position, showing an increase of $23 \%$ over the period under review. However, it is impossible to forget about the number of citizens who live on the resort territory without registration. According to expert estimates, about 800,000 people live on the territory of Sochi every year, which undermines the reliability of the official assessment of the anthropogenic load on the territory. Thus, due to a certain underestimation of the real situation, there is a threat of aggravation of some environmental problems. Detailed dynamics of the indicator of anthropogenic load on the territory of the Krasnodar region and resort territories is shown in Fig. 3. 


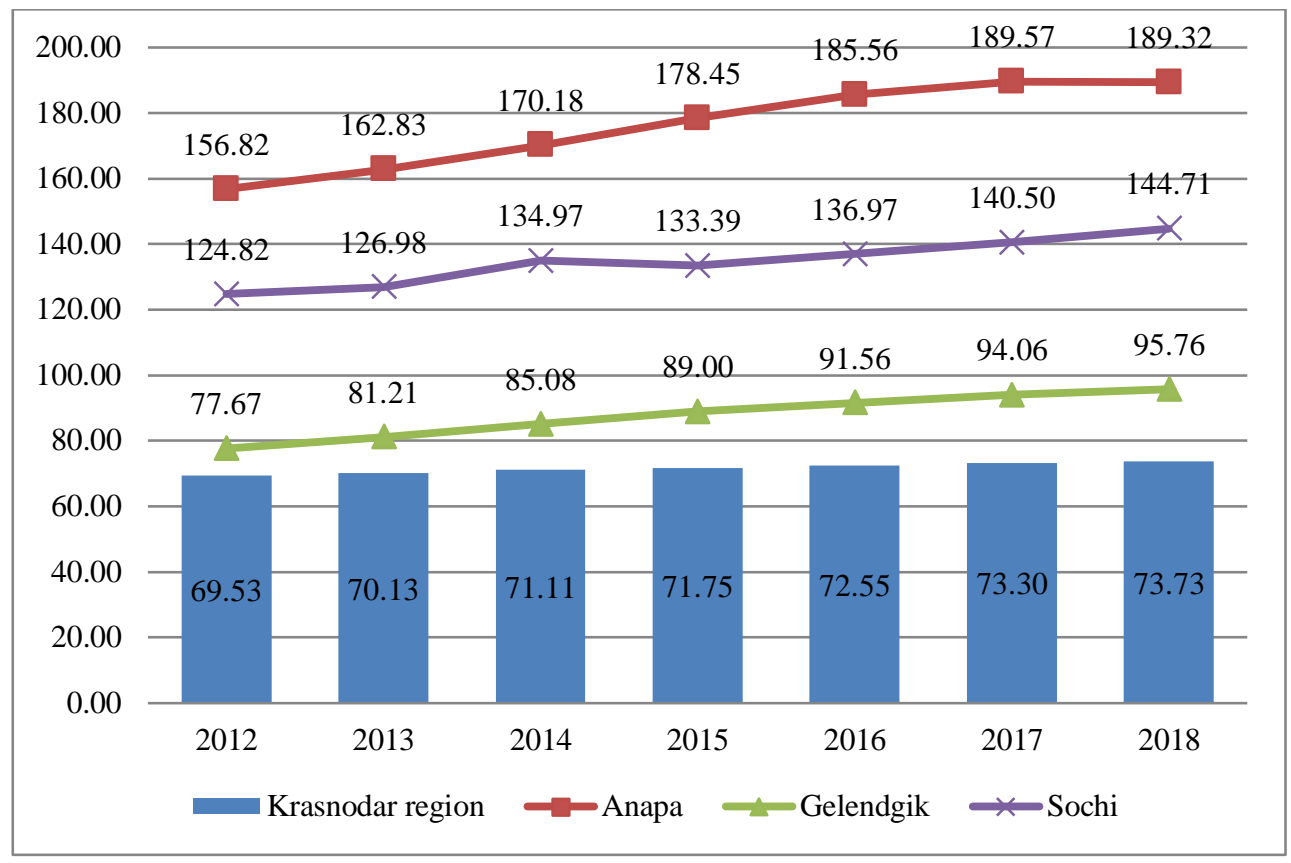

Fig. 3. Population density by region and municipalities, people $/ \mathrm{km}^{2}$ (calculated by the author based on [10-12]).

It is also impossible to forget about the recreational load on the territory of resort entities, which has increased by more than $40 \%$ in the period from 2008 to 2018 . Further growth without simultaneous nature restoration measures can lead to disastrous consequences: depletion of resort and recreational potential and deterioration of the environmental situation in the region.

The analysis of resort territories of the Krasnodar region has revealed the following environmental problems of municipalities and the region as a whole:

1. Water pollution, in particular caused by a high degree of population and congestion of coastal zones;

2. Air pollution, both from stationary pollution sources, and by increasing the load from vehicles, the impact of which directly depends on the number of people living on the territory; 3. Environmental pollution by industrial and household waste;

4. High anthropogenic load on the territory, compounded by a low level of environmental responsibility and awareness of both the local population and tourists.

Anthropogenic load and environmental pollution determine not only the ecological stability of resort regions, but also determine social and economic (including industrial) development. The depletion of recreational resources and the loss of "marketable" natural tourist sites will primarily affect the tourist demand for the territory and the revenues of municipal budgets. It is also clear that further deterioration of the environmental situation will reduce the popularity of the region as a place for living and business (the quality of life and investment attractiveness will decrease), and may provoke an outflow of population. This will significantly weaken the social and economic stability of the territory.

Since health is an important component in the quality of life assessment system, it is worth considering of the most significant environmental factors that shape the population health in the region and the whole country (Fig. 4). 


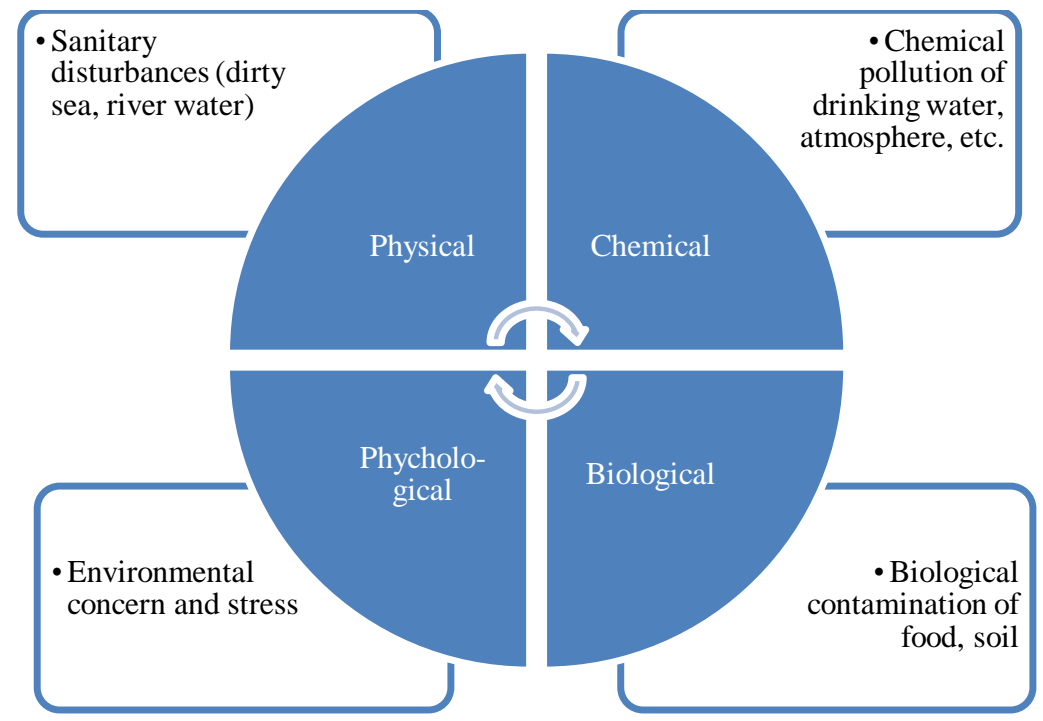

Fig. 4. The Impact of environmental conditions on people health as an important element of social stability (compiled by the author).

Indicators of environmental sustainability can also influence the demographic situation, the level and quality of life, the labor potential of the region, working conditions and other social indicators. The ecological state of recreational territories, such as resorts of the Krasnodar region, is extremely important for the efficient functioning of the economy. First, air and water pollution, as well as all sorts of man-made and biological infestations, can lead to a reduction in biological diversity. An example is the loss of a boxwood grove in the Sochi city as a result of infection with larvae of a Firefly introduced to the region during preparation for the 2014 Olympic Games. The reduction of resource and recreational potential will undoubtedly affect the tourist demand and popularity of the territory. As a result - reduction of tourist flow, reduced income of the local population employed in tourism and related industries, and the decline in regional economy growth.

The dependence of the environmental situation and the cultural and recreational potential of the territory has been proven and is constantly monitored by responsible structures. Natural and cultural heritage sites are exposed to natural and anthropogenic environmental factors. Natural factors that can cause premature degradation of such objects that form the resort product of the region include but not limited to:

1. Exposure to atmospheric agents such as extreme temperature and climate change;

2. Flooding (river flooding, shoreline erosion), water erosion;

3. Natural disasters - earthquakes, floods, fires, etc.

The group of anthropogenic factors includes industry, construction and transport activity carried out on the territory or near valuable historical, cultural and natural sites. As a result of the impact of negative factors of anthropogenic and natural nature in the future, there may be losses of archaeological and cultural monuments. In particular, destruction of dolmens in the Tuapse district, the Gelendzhik and Sochi resort cities caused by the tourists visits, and declining populations of the animal world provoked by environmental pollution is already noticeable.

Regulation of sustainable development of the resort territory should be based on the inherent consideration of the correlation of social, economic and environmental parameters of development. Rational use of natural resources and environmental sustainability of the territory can become a stimulating factor for region development. The lower the efficiency of environmental and anthropogenic risks management, the higher the probability of a negative 
scenario in the economy. Atmosphere emissions, pollution of water and earth resources leave a mark not only on the ecological health of the planet, but also cause irreversible processes in the social and economic development of community. Therefore, the role of the environmental component in the concept of sustainable development of resort territories is so important and requires close attention. Figure 5 clearly shows the impact of the environmental situation on the socio-economic prosperity of the region and its sustainability.

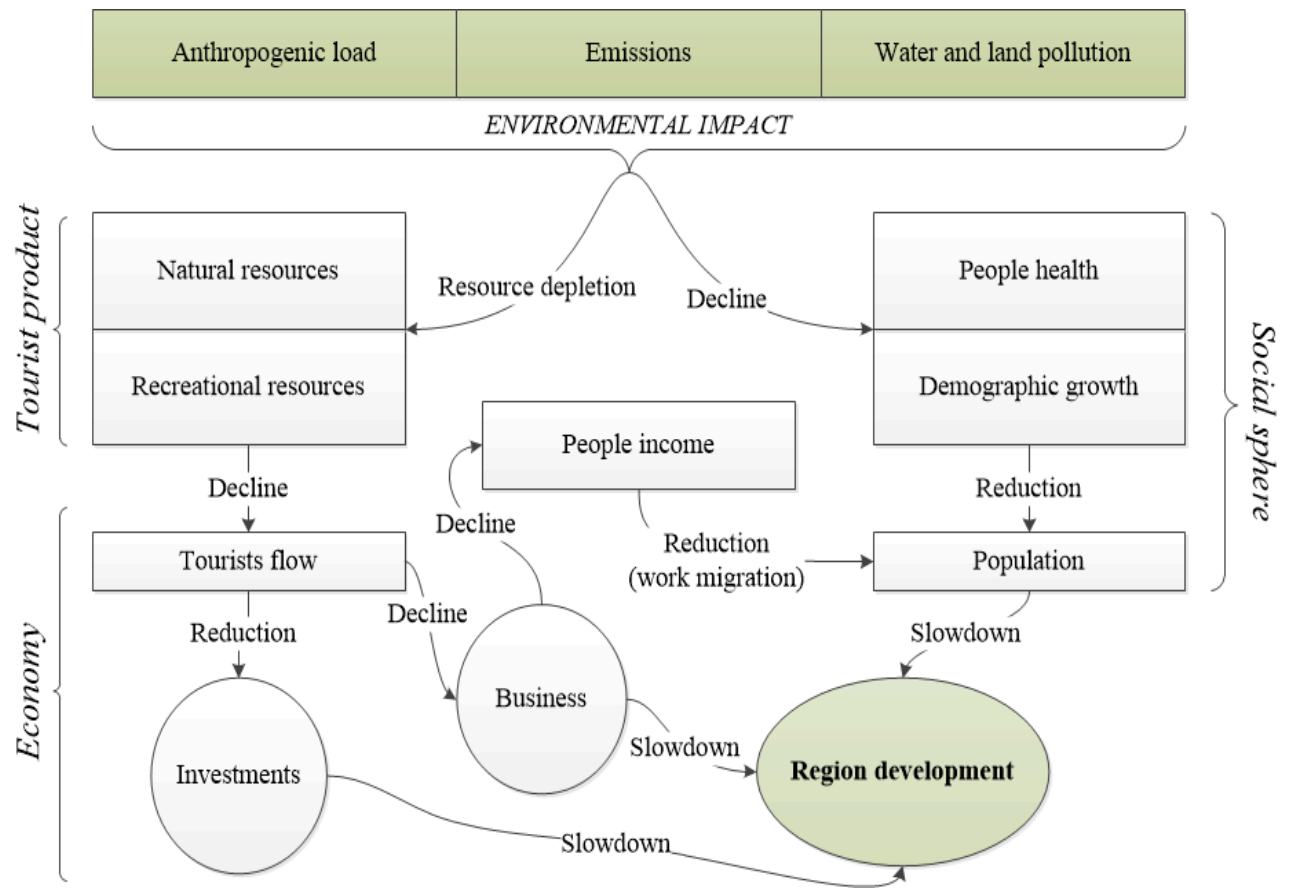

Fig. 5. The Impact of environmental sustainability on the development of the resort territory (compiled by the author).

Repeated human impacts on the environment in the absence of control, protection and restoration measures can provoke the emergence of negative processes in the socio-economic sphere, as shown in the figure. Consequently, existence of such dependencies between the components of the sustainable development of the territory allows concluding that the reduction of emissions, a moderate anthropogenic impact and restore natural and recreational resources will lead to increased demand for resort regions, investment inflow and increase of the life quality of local community.

\section{Conclusion}

The study allows assessing the ecological state of the resort territories of the Krasnodar region and describing the existing dependence of environmental characteristics with socio-economic parameters of the region. Now, the environmental situation in the region is assessed as favorable. However, the observed growth rates of anthropogenic load, the volume of emissions to the atmosphere and wastewater discharge may lead to a disproportion in the needs for natural and recreational resources and the possibility of its reproduction in the future. Underestimating the priority of environmental sustainability leads to erroneous managerial decisions in the course of territory development. Resort specialization of certain subjects of the Krasnodar region is directly determined by the natural, climatic and resource features of 
the region. This fact ultimately makes all economic activity of these territories conditional upon the stability of resource and recreational potential.

The further development of the resort territories of the region largely depends on the efficiency of resource use and priority of its management. Based on the results of the study, it is possible to formulate a list of recommendations aimed at optimization of the environmental sphere of the region and development of eco-oriented activities:

1. Equipping the main air pollution sources with gas cleaning equipment (with the support of public-private structures, if necessary), as an example of a compromise between economic development, favorable living conditions of the local population and the preservation of the environment.

2. Shifting the focus of environmental activities from promotion and education to more practical measures aimed at restoring the environment. According to the reports of the Ministry of natural resources of the Krasnodar region, the list of implemented measures is dominated by preventive measures (exhibitions, lectures for children, and others).

3. Revision of the existing set of rules for water use and disposal, in particular the Water code, in order to achieve the maximum level of comfort for functioning enterprises without compromising the quality of seawater.

Regular restoration work on the main sites of tourists' interest after the holiday season.

\section{Acknowledgements}

The reported study was funded by RFBR and Krasnodar region according to the research project № 19-410-230049.

\section{References}

1. H. Stoddart, K. Schneeberger, F. Dodds, A. Shaw, M. Bottero, J. Cornforth, R. White, A pocket guide to sustainable development governance. Stakeholder Forum 2011 (2011) https://scholar.google.com/scholar_lookup?hl=en\&

publication_year=2011\&author=H.+Stoddart\&title=A+pocket+guide+to+sustainable+ development+governance

2. C.F.Thomas, Naturalizing Sustainability Discourse: Paradigm, Practices and Pedagogy of Thoreau, Leopold, Carson and Wilson (Arizona State University, 2015) https://repository.asu.edu/attachments/150805/content/Thomas_asu_0010E_15079.pdf

3. E. Vidishcheva, Yu. Dreizis, A. Kopyrin, E. Vorobey, E3S Web of Conferences 135, 04031 (2019)

4. E. Vidishcheva, Yu. Dreizis, A. Kopyrin, E3S Web of Conferences 135, 03042 (2019)

5. On the State of Nature Management and Environmental Protection of Krasnodar Region in 2018: Report/Krasnodar (2019) htt://www.mprkk. ru/media/main/attachment/attach/doklad_oos-2018-_itog.pdf

6. Emissions of pollutants in the federal districts of the Russian Federation (2018) http://25.rpn.gov.ru/sites/default/files/od-human-read/peredvizhenye_2018_god.xlsx

7. On the State of Nature Management and Environmental Protection of Krasnodar Territory in 2017: Report/Krasnodar (2018) http://mprkk. ru/media/main/attachment/attach/doklad_krkr_2017_itog.pdf

8. Environmental protection. Database of indicators of municipal entities, https://www.gks.ru/dbscripts/munst/munst03/DBInet.cgi\#1 
9. Emissions of pollutants in the federal districts of the Russian Federation (2019) https://www.gks.ru/bgd/regl/b12_14p/Iss/ Stg/d01/10-05.htm

10. On the State of Nature Management and Environmental Protection of Krasnodar Region in 2018: Report/Krasnodar (2019) http://www.mprkk. ru/media/main/attachment/attach/doklad_oos-2018-_itog.pdf

11. Official website of Ministry of Tourism and Olympic Heritage of Krasnodar Region, http://min.kurortkuban.ru

12. Statistics for the Russian Federation//Federal Tourism Agency (2019) https://www.russiatourism.ru/contents/statistika/statisticheskie-dannye-po -rf-2018/ 